\title{
Pedagogia da alteridade e eseola enquanto experiência de amor à vida e ao mundo
}

\section{Pedagogy of alterity: the school as an experience of loving life and the world}

\author{
Adecir Pozzer* \\ $\mathrm{SED} / \mathrm{SC}$; FURB
}

Recebido em: 30/09/2021. Aceito em: 04/11/2021.

Resumo: A escola tem se constituído, ao longo da história, enquanto tempo/ espaço de experiências de aprendizagens por proporcionar o cultivo de um tempo livre das determinações do cotidiano, oportunizando experiências da e com a outridade, consigo mesmo e com o mundo. Frente às inúmeras acusações relacionadas à escola e as tentativas de instrumentalizá-la por interesses alheios à sua finalidade, este artigo apresenta algumas reflexões que dizem respeito à sua importância na formação das atuais e novas gerações, tendo em vista o cuidado da vida em suas múltiplas expressões e coletividades. A metodologia adotada é bibliográfica e em perspectiva hermenêutica, pois compreendemos que toda reflexão em torno da educação possui sempre um caráter ensaístico e inaugural. Com isso, consideramos que uma pedagogia da alteridade oportuniza, aos estudantes, experiências de amor à vida e ao mundo.

Palavras-chave: Escola. Pedagogia da Alteridade. Experiência.

\begin{abstract}
The school has been constituted, throughout history, as a time/space of learning experiences by stimulating the cultivation of free time, a time away from everyday determinations, providing opportunities for experiences of and with the otherness, with oneself and with the world. Considering the several accusations to the school and the attempts to use it for interests beyond its purpose, this article presents some reflections regarding its importance in the formation of the current and also the new generations, considering the care of life in its multiple
\end{abstract}

* Doutor em Educação (Universidade Federal de Santa Catarina - UFSC, Florianópolis, SC, 2020). Mestre em Educação (Universidade Federal de Santa Catarina - UFSC, Florianópolis, SC, 2013). Graduado em Ciências da Religião - Ensino Religioso (Fundação Universidade Regional de Blumenau, FURB, Blumenau, SC, 2010). Assistente técnico-pedagógico da Secretaria de Estado da Educação, atuando na assessoria da Diretoria de Ensino. Professor em caráter temporário da FURB.

E-mail: pozzeradecir@hotmail.com. 
expressions and collectivities. The adopted methodology is bibliographical in a hermeneutic perspective, as we understand that every reflection around the area of the education always has an essayistic and inaugural character. Thus, we believe that a pedagogy of alterity provides, to the students, experiences of love for life and the world.

Keywords: School. Pedagogy of alterity. Experience.

\section{Introdução}

A proposta da Campanha da Fraternidade de 2022, ação promovida pela Conferência Nacional dos Bispos do Brasil (CNBB), com o tema Fraternidade e Educação, e o lema Fala com sabedoria, ensina com amor, tem grande relevância ao pensamento educacional contemporâneo. Traz à memória a sabedoria articulada $\mathrm{a}$ uma perspectiva pedagógica centrada na amorosidade, que pode ser traduzida em relações de confiança, alteridade e reconhecimento mútuo.

A abordagem da temática possui relevância histórica, especialmente porque se coloca em um momento em que a autonomia da escola, de modo específico, a pluralidade de ideias e a liberdade de ensinar, assegurados na Constituição Federal de 1988 e na Lei de Diretrizes e Bases da Educação Nacional de 1996, são ameaçadas por patrulhamentos ideológicos e interesses particularizados. Assim, a proposta deste texto é contribuir com algumas reflexões acerca do papel da escola enquanto tempo e espaço de experiências, de criações e de interações. Ou seja, nos colocamos em defesa da escola enquanto tempo/espaço que assegura o direito à educação, às múltiplas aprendizagens e a uma formação para a cidadania.

Por isso, em um primeiro momento argumentamos em torno da necessidade de problematizar o cotidiano e, de forma articulada, assegurar aos estudantes o tempo livre que caracteriza o escolar, isto é, tempos e espaços democratizados e públicos para o desenvolvimento de aprendizagens e habilidades que ampliam as possibilidades de interação no e com mundo, transformando-o e ressignificando-o.

Em um segundo movimento, refletimos acerca da pedagogia da alteridade enquanto possibilidade de construção de outras perspectivas educacionais, processos formativos que partam da sensibilidade e responsabilidade ética, onde o encontro inaugural seja marcado pela acolhida, hospitalidade, respeito e solidariedade. 


\section{Escola enquanto tempo/espaço de experiências outras}

Ao mesmo tempo em que a escola tem se constituído em um tempo/ espaço de múltiplas aprendizagens, de suma importância para a sociabilidade das crianças e jovens, ao ensino e desenvolvimento das ciências, à recriação e ressignificação do mundo, ela tem convivido com ataques em distintos momentos da história. Em geral, esses ataques deferidos contra à escola e, por consequência, à própria educação, referem-se à incapacidade de ela dar conta de idealismos e responsabilidades impostos ou transferidos pela sociedade, em especial de que ela não prepara para a "vida real". Há também os que a atacam por estar a serviço do capital cultural, econômico e das elites que buscam manter certo status $q u o$, um dos motivos de desinteresse por parte dos jovens, somado a alegação de que não prepara para os novos mercados de trabalho e que tem difundido ideologias contrárias aos valores de uma determinada concepção de família.

Diante dos ataques que procuram condenar ou abandonar a escola, nos utilizamos das contribuições de Masschelein e Simons, especialmente da obra "Em defesa da escola: uma questão pública" (2013), para argumentar em defesa da escola, especialmente quando vivemos uma pandemia que, ao mesmo tempo em que colocou em xeque as estruturas atuais da educação escolar, nos recordou da sua importância às sociedades contemporâneas. Neste sentido, os referidos autores esclarecem seu posicionamento afirmando que:

Nós nos recusamos, firmemente, a endossar a condenação da escola. Ao contrário, defendemos a sua absolvição. Acreditamos que é exatamente hoje - numa época em que muitos condenam a escola como desajeitada frente a realidade moderna e outros até mesmo parecem querer abandoná-la completamente - que o que a escola é e o que ela faz se torna claro. ${ }^{1}$

Obviamente que por ser uma instituição criada pelos humanos, há sempre um risco de a escola desaparecer. Outras propostas podem se apresentar como que "substitutas" dela, especialmente na era digital e da virtualização das relações humanas, de trabalho e de aprendizagens.

\footnotetext{
MASSCHELEIN, Jan; SIMONS, Maarten. Em defesa da escola: uma questão pública. Trad. Cristina Antunes. Belo Horizonte: Autêntica, 2013. p. 10.
} 
Compreendemos que as inovações trazidas pelas novas tecnologias educacionais delimitam as necessidades de a escola ser reinventada e ressignificada, pois ela não é estática, mas dinâmica, porque produzida e cultivada por homens e mulheres, crianças e jovens. E isso, fundamentalmente, não é uma ameaça à escola, pelo contrário, pode e deve contribuir com a sua atualização e alcance de sua finalidade, daquilo que somente ela pode oferecer. Mas, o que somente ela pode oferecer?

De acordo com Michel de Certeau, "o cotidiano é aquilo que nos é dado cada dia, nos pressiona dia após dia, nos oprime, pois existe uma opressão no presente". [...] "O cotidiano é aquilo que nos prende intimamente, a partir do interior". ${ }^{2}$ Essa opressão do cotidiano ocorre de formas distintas, algumas impostas pela própria natureza, outras são produzidas pelo próprio humano e estão relacionadas ao ambiente familiar, à cultura, ao trabalho e às questões éticas e morais. Diante disso, a escola pode oferecer o "tempo livre", com a finalidade de "reunir jovens em torno de uma 'coisa' comum, isto é, algo que aparece no mundo que seja disponibilizado para uma nova geração".

A escola [...] surge como a materialização e espacialização concreta do tempo que, literalmente, separa ou retira os alunos para fora da (desigual) ordem social e econômica, (a ordem da família, mas também a ordem da sociedade como um todo) e para dentro do luxo de um tempo

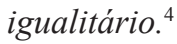

O tempo livre caracteriza o escolar (skholé) ao introduzir as crianças no mundo. O sentido do escolar remete à pólis grega, entendido enquanto tempo e espaço democratizado, público e igualitário. Todos, independentemente de crença, condição social e origem étnico-racial, têm a oportunidade de desenvolver aprendizagens e habilidades que possibilitam compreender e interagir no mundo, transformando-o, inovando-o e ressignificando-o. O caráter constituinte do escolar gerou incômodos à aristocracia grega ao retirar as crianças e jovens da "ordem desigual natural". Usurpou o privilégio de grupos dominantes, como as "elites aristocráticas e militares"5 e ofereceu um tempo não produtivo, segundo

2 CERTEAU, Michel de. A invenção do cotidiano. 1, Artes de fazer. Petrópolis: Vozes, 1994. p. 31.

3 MASSCHELEIN; SIMONS, 2013, p. 11.

4 MASSCHELEIN; SIMONS, 2013, p. 29.

5 MASSCHELEIN; SIMONS, 2013, p. 26. 
a ordem mercantil. Ou seja, "[...] o tempo escolar é o tempo tornado livre e não é tempo produtivo" .

O escolar é a oportunidade dos estudantes se dedicarem àquilo que dificilmente realizam em outros tempos/espaços. Fazem experiências em torno de uma matéria comum, articulando conhecimentos e saberes a partir de diferentes perspectivas. A natureza do escolar é inovador e revolucionário e impede que a escola seja controlada pelo medo, pelo ódio ou por hostilidades que existem desde a sua invenção. Ela resiste às colonialidades e subalternizações de saberes, experiências e epistemes. É por isso que o escolar nutre um caráter fundamentalmente democrático, o que justifica certo desconforto e desprezo que por vezes lhe é imputado, especialmente a partir da universalização da educação escolar, em que as classes populares passaram a ter acesso ao tempo livre democratizado.

Para que as crianças e jovens possam desfrutar do tempo livre, aquilo que é marcado pelo cotidiano, pelo privado ou familiar passa a ser suspenso e profanado, temporariamente, a fim de que se possa experimentar algo diferente e criar espaço para o novo. Neste sentido, a suspensão torna-se estratégica e pedagógica. Significa desligar-se provisoriamente de algo, do tempo produtivo, tornando-o inoperante. Esse movimento se caracteriza como "um ato de desprivatização, isto é, desapropriação" e do âmbito particular, mas dedicar atenção a outra coisa, concentrar-se em algo comum para aprender, ampliar os horizontes de sentido e construir algo que difere do previamente dado e por vezes naturalizado como padrão ou verdade.

É por meio da suspensão que a escola oferece aos estudantes a possibilidade de sair (por um momento) de sua bolha familiar, de seu cotidiano mais comum, e adentrar um novo espaço, novos acessos, onde a descoberta, a investigação, um mundo de conhecimentos humanos the é apresentado, para além daquilo que lhe é familiar. ${ }^{8}$

A profanação, no entendimento de Masschelein e Simons (2013), não possui um caráter depreciativo ou vulgar, mas trata-se de tornar algo

6 MASSCHELEIN; SIMONS, 2013, p. 33.

7 MASSCHELEIN; SIMONS, 2013, p. 33.

8 POZZER; Adecir; POZZER, Suzan Alberton. Suspensão como possibilidade ao ensino religioso não confessional. In: CECCHETTI, Elcio; SIMONI, Josiane Crusaro. Ensino Religioso não confessional: múltiplos olhares. São Leopoldo: Oikos, 2019. p. 67. 
público, disponível para além do uso e domínio privado. Os conhecimentos ou determinadas competências importantes para o cuidado da saúde da população, por exemplo, tornaram-se públicos com o passar do tempo. Isto é, houve um processo de expropriação do uso restrito para tornar-se público, para ser ensinado e aprendido por quem desejasse. No que diz respeito a educação básica, há também um sentido de introduzir as crianças e jovens em matérias que, em uma linguagem mais coloquial, diz respeito ao mundo adulto. A profanação, assim, refere-se a abertura ao mundo, acesso público àquilo que com o passar do tempo fora domesticado, sacralizado, tratado e domado em uma esfera privada.

Neste sentido, vale destacar que,

A típica experiência escolar - a experiência que é possibilitada pela escola - é exatamente aquele confronto com as coisas públicas disponibilizadas para uso livre e novo. [...] O que é tratado na escola está enraizado na sociedade, no cotidiano, mas transformado pelos atos simples e profundos de suspensão (temporária) e profanação. ${ }^{9}$

Desde uma perspectiva da hermenêutica contemporânea, a experiência se caracteriza por seu caráter inaugural e por uma dimensão de negatividade, isso porque, em especial no campo das humanidades e na educação escolar, a experiência não é regulada previamente em relação ao experimentar. Neste sentido, Gadamer ${ }^{10}$ assinala que não é possível "fazer" duas vezes a mesma experiência. Quer dizer que quando alguém "faz" uma experiência, ele já a "possui" e, em caso de repetição, já "saberá" onde vai dar. Sendo assim, não há mais possibilidades de descobertas. E é justamente isso que caracteriza o escolar, a abertura para novas experiências, condições e possibilidades para ensaiar, inventar, inovar. É claro que a validade científica de uma experiência, especialmente nas ciências exatas e da natureza, por exemplo, se encontra na repetição e produção de resultados iguais ou similares. Nestas áreas, o inesperado torna-se previsível, embora permaneça inconcluso, pois nenhuma ciência é estática.

A escola possibilita ao estudante ser um experimentador, e o saber da experiência é sempre contextual, histórico e marcado pela provisoriedade. Diante disso, o ser humano mais "experimentado é sempre o

9 MASSCHELEIN; SIMONS, 2013, p. 40.

10 GADAMER, Hans-George. Verdade e Método: traços fundamentais de uma hermenêutica filosófica. 3. ed. Trad. Flávio Paulo Meurer. Petrópolis: Vozes, 1997. p. 522. 
mais radicalmente não dogmático, que precisamente por ter feito tantas experiências e aprendido graças a tanta experiência, está particularmente capacitado para voltar a fazer experiências e delas aprender". ${ }^{11}$ É neste contexto do escolar, portanto, que ocorrem as experiências da e com a outridade, exigindo, também, uma pedagogia da alteridade.

\section{Pedagogia da alteridade: por uma educação voltada ao amor à vida e ao mundo}

Com o surgimento da Modernidade, evidenciou-se uma mudança na forma de conceber o saber relativo à natureza. De experiências de contemplação e reflexão do universo, teorias e conhecimentos fragmentados passaram a mediar e regrar a intervenção no universo com certa eficiência. Esse novo paradigma, caracterizado como racional-científico-experimental, possibilitou ao ser humano transformar significativamente seu modo de pensar e de se relacionar com as novas oportunidades, encontrando-se na centralidade desses processos. Desta forma, os próprios processos educacionais passaram a convergir para a submissão da natureza frente à imposição da lógica do sujeito humano.

Ao ser reduzido ao horizonte das possibilidades do Eu conhecedor, o conhecimento da natureza impossibilita a natureza ser o que de fato é em si mesma. Ou seja, a coisa conhecida já não é em si mesma, pois se encontra despida de sua alteridade. Em certo sentido, a coisa conhecida passa a ser a medida do seu conhecedor. Essa negação da independência dos entes que Levinas considera uma violência, pois mesmo existindo, as coisas são parcialmente negadas. ${ }^{12}$

De acordo com $\mathrm{Fabri}^{13}$, a razão visa à neutralização ao tentar englobar o Outro, tornando-o conceito. Só é possível compreender e abarcar o Outro na medida em que se neutraliza o ser deste Outro. Constata-se, com isso, que se está sob o domínio do Mesmo, ou seja, em uma perspectiva de totalização, em que o ser do sujeito está sob os seus domínios e, ao mesmo tempo, é transformado por ele em sujeito cognoscente, subordinado e reduzido à expressão do ser.

\footnotetext{
11 GADAMER, 1997, p. 525.

12 LEVINAS, Emmanuel. Descobrindo a existência com Husserl e Heidegger. Lisboa: Instituto Piaget, 1997.

13 FABRI, Marcelo. Desencantando a ontologia. Porto Alegre: EDIPUCRS, 1997.
} 
Em consonância com a Filosofia Levinasiana, podemos dizer que o conhecimento, enquanto acolhimento e respeito à alteridade, está estritamente vinculado a um ensinamento, a uma linguagem, a uma presença do Outro e a um discurso, isso porque a existência concreta em carne e osso é o primeiro ser inteligível, e não o conceito. O conhecimento, portanto, tem seu início em um contexto que há corpos que necessitam de comida, água e ar para respirar. O fato é que não se inicia em um mundo abstrato, desconexo da corporeidade ${ }^{14}$.

Por este motivo que Levinas insistirá em dizer que o mundo é o primeiro alimento. Ou seja, alimentamo-nos do mundo ante de mais nada, pois é ele que nos concede o ar, a luz, o sono dentre outros elementos necessários para viver. Posteriormente é que vêm as representações do mundo e das coisas. Mas, vivemos do alimento do mundo e não de sua representação. "Os elementos do mundo não possuem formas, nem face, e é por isso que eles não são abordáveis como meros objetos ou fixados pelo pensamento."15

O mundo é um conjunto de alimentos antes de ser um sistema de utilidades a serem exploradas. Os elementos do mundo, como as vestes, o ar, a luz, a casa e muitos outros, não se reduzem simplesmente a objetos úteis, pois, se são elementos fundamentais do viver, acabam em fruição ${ }^{16}$.

Mas, embora haja uma hegemoniza da universalização e racionalização técnico-científica, diferentes grupos e movimentos resistem aos imperialismos e colonialidades, ancorados nas pegadas do humanismo ético que permanece no Ocidente, encontrando na justiça e na solidariedade os fundamentos para a defesa da dignidade humana ${ }^{17}$.

Muito embora, o próprio humanismo precisa ser problematizado, pois, de acordo com Levinas ${ }^{18}$, ele mesmo tornou-se desumano, não apenas por conta dos grandes conflitos ocorridos no sec. XX, como o stalinismo, o fascismo, o hitlerismo, bombardeios atômicos, genocídios, colonialismos, etc., mas por conta, também, de uma ciência que calcula o real de forma fragmentada e descontínua e de uma política que não

14 LEVINAS, Emmanuel. Totalidade e infinito. Trad. José Pinto Ribeiro. Lisboa: Edições 70, 1980.

15 ALVES, Marcos Alexandre. Pedagogia da alteridade: o ensino como acolhimento ético do outro e condição crítica do saber. Tese (Doutorado em Educação) - Universidade Federal de Pelotas, Pelotas, 2011, p. 51.

16 LEVINAS, 1980.

17 SIDEKUM, Antonio (org.). Interpelação ética. São Leopoldo: Nova Harmonia, 2003.

18 LEVINAS, 1980. 
suprime a exploração e as guerras, mas que se afunda em burocracias e interesses alheios às necessidades da sociedade em geral. Para além dessas questões, a problematização do humanismo passa pela incapacidade humana de se opor fundamentalmente a essas desumanidades, ou seja, o humano não é suficientemente humano na radicalidade do termo.

É nesta perspectiva que o escolar precisa ser continuamente ressignificado para possibilitar a imaginação e criação de outros mundos, no sentido de renovar e inovar para cuidar e gerar mais vida. E, a pedagogia da alteridade se apresenta como uma possibilidade para construir outras perspectivas educacionais e, por que não, ser um dos caminhos para as profundas transformações nos processos formativos, que partam da sensibilidade e responsabilidade em perspectivas dos direitos humanos e da Terra.

Uma pedagogia da alteridade tem seu início no encontro inaugural que ocorre entre educando e educador, marcado pela acolhida ao Outro. No encontro inaugural, que é contínuo no processo formativo, o educador em especial, tem de ser guiado pela sensibilidade ética, cujo objetivo visa ao conhecimento das singularidades de cada educando. Em uma pedagogia da alteridade, um não exerce o poder sobre o outro, pois o educando não é um objeto de conhecimento, nem um sujeito a ser conhecido em todas as suas especificidades pessoais para garantir êxito profissional do educador e, muito menos um espaço a ser preenchido com informações. A educação tem de ser "um acontecimento ético, uma experiência ética singular, não um experimento em que a referência à ética lhe venha de fora." 19

A pedagogia da alteridade possui um caráter hospitaleiro, caracteriza-se pela abertura e acolhida responsável do Outro que se apresenta como estrangeiro, recém-chegado, estranho. A ética, nesse sentido, torna-se a condição de possibilidade da formação, não sendo reduzida ou restrita a uma simples finalidade, dentre tantas outras.

Assim, pensar efetivamente uma pedagogia da alteridade enquanto acolhida, hospitalidade, reconhecimento e responsabilidade ética " $[. .$. implica introduzir mudanças não apenas na linguagem, mas na práxis e na reflexão pedagógica" ${ }^{20}$ que, necessariamente, perpassará no que

19 MĖLICH, Joan Carles; BÁRCENA, Fernando. La educación como acontecimiento ético: natalidad, narración y hospitalidad. Barcelona: Paidós, 2000. p. 126.

20

ALVES, 2011, p. 158. 
consideramos o "coração" dos processos formativos, o currículo, além de uma cultura em geral e determinados mecanismos sociais que insistem em reproduz cegueiras, conservadorismos e fundamentalismos.

Uma pedagogia da alteridade fortalece o escolar abrindo espaço para o sentimento, a diferença, o afeto, a corporeidade e o cuidado do Outro, de si mesmo e do mundo. Visa formar para a abertura e acolhida do Outro em seus problemas, seus assuntos, seus sonhos, suas angústias, sua infinitude e toda realidade que o entorna e o transcende. Resgata-se, com isso, o direito fundamental do ser humano ser, de fato, Outro, diferente, único e irrepetível, digno de reconhecimento em sua alteridade.

\section{Considerações finais}

Concluímos que oportunizar tempo livre aos estudantes é extremamente revolucionário, isto porque em um mundo com ritmos acelerados, "programado" e paradoxal, em que ao mesmo possibilita conexões com distintos lugares do mundo, provoca distanciamentos dos que vivem nas proximidades. Diante disso, é preciso salvaguardar o escolar enquanto plataforma para encontros e diálogos interativos, interculturais e intergeracionais.

Há que se reencantar a educação e, para isso, é necessário dar ênfase na criação de experiências de aprendizagens, problematizando todas as formas e tentativas que ainda tendem a reproduzir adultocentrismos, hierarquizações e etnocentrismos legitimados e difundidos no decorrer da tradição educativa. Para isso, é necessário fortalecer a pedagogia da alteridade como estratégia para fazer frente a todas as tentativas de instrumentalização da educação voltada aos interesses de grupos com maior poder aquisitivo.

Por fim, consideramos importante ressaltar o caráter amoroso e, ao mesmo tempo, político da educação, não no sentido partidário, mas na sua relação com o projeto de sociedade que desejamos construir. Por isso, finalizamos esta breve reflexão com os dizeres de Hannah Arendt de que "a educação é a posição em que decidimos se amamos o mundo o bastante para assumir a responsabilidade por ele, e pela mesma razão, salvá-lo da ruína que, a não ser pela renovação, a não ser pela vinda do novo e dos jovens, seria inevitável"21.

Ousamos fazê-lo!

21 ARENDT, Hannah. Entre o passado e o futuro. São Paulo: Perspectiva, 2000. p. 247. 


\section{Referências}

ALVES, Marcos Alexandre. Pedagogia da alteridade: o ensino como acolhimento ético do outro e condição crítica do saber. Tese (Doutorado em Educação) - Universidade Federal de Pelotas, Pelotas, 2011.

ARENDT, Hannah. Entre o passado e o futuro. São Paulo: Perspectiva, 2000.

CERTEAU, Michel de. A invenção do cotidiano. 1, Artes de fazer. Petrópolis: Vozes, 1994.

FABRI, Marcelo. Desencantando a ontologia. Porto Alegre: EDIPUCRS, 1997.

GADAMER, Hans-George. Verdade e Método: traços fundamentais de uma hermenêutica filosófica. 3. ed. Trad. Flávio Paulo Meurer. Petrópolis: Vozes, 1997.

LEVINAS, Emmanuel. Descobrindo a existência com Husserl e Heidegger. Lisboa: Instituto Piaget, 1997.

LEVINAS, Emmanuel. Totalidade e infinito. Trad. José Pinto Ribeiro. Lisboa: Edições 70, 1980.

MASSCHELEIN, Jan; SIMONS, Maarten. Em defesa da escola: uma questão pública. Trad. Cristina Antunes. Belo Horizonte: Autêntica, 2013.

MÈLICH, Joan Carles; BÁRCENA, Fernando. La educación como acontecimiento ético: natalidad, narración y hospitalidad. Barcelona: Paidós, 2000.

POZZER; Adecir; POZZER, Suzan Alberton. Suspensão como possibilidade ao ensino religioso não confessional. In: CECCHETTI, Elcio; SIMONI, Josiane Crusaro. Ensino Religioso não confessional: múltiplos olhares. São Leopoldo: Oikos, 2019.

SIDEKUM, Antonio (org.). Interpelação ética. São Leopoldo: Nova Harmonia, 2003. 